\title{
Raciocínio Lógico nas Escolas: Uma Introdução ao Ensino de Algoritmos de Programação
}

\author{
Nyara Silva $^{1}$, Ana Carina Lima ${ }^{1}$, Niellen Souza ${ }^{1}$, Decíola Sousa ${ }^{1}$ \\ ${ }^{1}$ Instituto Ciberespacial - Universidade Federal Rural da Amazônia (UFRA) \\ Avenida Presidente Tancredo Neves, 2501 - Belém - PA - Brasil \\ \{nyhcardoso002, aninhaufra, menescalniellen\}@gmail.com, \\ deciolalufra.edu.br
}

\begin{abstract}
The teaching of computational thinking have been of great importance in the expansion of the students' cognitive capacities in different stages of their development. This article reports the experience of Computing degree students, entitled "Workshop of Logical Reasoning and Programming", with the objective of assisting math students learning skills at the Brazilian Mathematics Olympiad of Public Schools (OBMEP) and introduce Computing for basic education. As a result was noted students positive change at reasoning and problem-solving skills, as well as interest and curiosity increase for areas related to computing.
\end{abstract}

Resumo. O ensino do pensamento computacional tem sido de grande importância na expansão das capacidades cognitivas dos alunos em diferentes etapas de seu desenvolvimento. O presente artigo relata a experiência de discentes do curso de Licenciatura em Computação, intitulada "Oficina de Raciocínio Lógico e Programação", com objetivo de auxiliar os alunos do $8^{\circ} e$ $9^{\circ}$ ano na Olimpíada Brasileira de Matemática das Escolas Públicas (OBMEP), e introduzir a Computação na Educação Básica. Como resultado notou-se nos alunos uma mudança positiva quanto ao raciocínio e à capacidade de solucionar problemas, além do aumento do interesse e curiosidade para as áreas relacionadas à Computação.

\section{Introdução}

O ensino do raciocínio lógico nas escolas é relevante no desempenho dos alunos em várias disciplinas escolares, assim como no desenvolvimento pessoal, visto que a lógica permeia as mais variadas áreas de conhecimento, caracterizando-se como um campo interdisciplinar [PUGA e RISSETTI 2009].

Para a introdução da lógica de programação através da linguagem algorítmica (português estruturado ou "Portugol") no ensino básico, são necessários alguns cuidados, tendo em vista que além dos educandos não possuírem contato direto com o conteúdo, não possuem também o conhecimento prévio sobre o mesmo.

A linguagem algorítmica constitui-se como a ponte entre o conhecimento abstrato (inerente à ciência da computação e à própria lógica) e o conhecimento concreto (empírico, contextualizado) [CHAVES et al. 1983]. A pseudo-linguagem 
Portugol (baseada na língua materna do aluno e na representação gráfica) facilita a aprendizagem, pois permite o foco principal na expressão lógica do algoritmo, e não no idioma, no ambiente de programação ou qualquer outro fator [MANSO et al. 2009], ou seja, permite um olhar diferenciado para a construção de tais conhecimentos.

O ensino da lógica surge como uma maneira de exercitar o conhecimento dos alunos em matemática e estimular o pensamento computacional. A representação algorítmica de um determinado problema, aliada à narração verbal, pode ocasionar "uma transição mais 'suave' para a compreensão da linguagem matemática" [BARCELLOS e SILVEIRA 2012], trabalhando a interpretação de texto e conhecimentos técnicos da área da computação.

Portanto, o estudo de linguagem de programação por meio de interpretação de algoritmos, assim como o estímulo do raciocínio lógico nas escolas, pode auxiliar no desenvolvimento de habilidades e competências exigidas no currículo do aluno da educação básica e até mesmo do graduando ou profissional no mercado de trabalho.

Partindo desse pressuposto, o objetivo do artigo é apresentar a experiência desenvolvida no Estágio Supervisionado Obrigatório I (ESO I) intitulada "Oficina de Raciocínio Lógico e Programação" que teve por objetivo orientar os alunos do $8^{\circ}$ e $9^{\circ}$ ano do Ensino Fundamental de uma escola pública estadual de Belém para a Olimpíada Brasileira de Matemática das Escolas Públicas (OBMEP) e para a inserção da Computação na Educação Básica.

No que se concentra o desenvolvimento deste trabalho, além da introdução, segue organizado da seguinte maneira: na Seção 2 são descritos os trabalhos relacionados, na Seção 3 os materiais e métodos utilizados na Oficina, na Seção 4 os resultados obtidos com a experiência e por fim, na Seção 5 as considerações finais e trabalhos futuros.

\section{Trabalhos Relacionados}

Alguns trabalhos relacionam o ensino do raciocínio lógico ao aprendizado de matemática e de linguagens de programação, por meio de diversos conceitos computacionais, matemáticos ou mesmo interdisciplinares. Outros ampliam a discussão para a capacidade de interpretação de texto a partir da abstração de determinado problema e da formulação de possíveis soluções [PAULA et al. 2009].

O pensamento computacional envolve o uso do computador como um recurso capaz de ampliar as capacidades cognitivas humanas, bem como a criatividade, a produtividade, a operacionalidade e a inventividade França et al. [2012]. Mas, também pode ser trabalhado através de representações nas quais associa-se o funcionamento do processamento de um computador às práticas cotidianas, como ocorre na Computação Desplugada.

Quando aplicada em sala de aula, a Computação Desplugada trabalha conceitos computacionais de forma descontraída e fácil [BELL et al. 2011]. Em Bezerra [2014], Raiol et al. [2016], os autores relatam experiências relacionadas ao ensino da Ciência da Computação por meio da Computação Desplugada na Educação Básica em escolas 
VI Congresso Brasileiro de Informática na Educação (CBIE 2017)

Anais dos Workshops do VI Congresso Brasileiro de Informática na Educação (WCBIE 2017)

públicas, utilizando as atividades do Livro Computer Science Unplugged, criado por Tim Bell, Ian H. Witten e Mike Fellows.

Outra tendência educacional bastante interessante é o ensino de introdução à programação na Educação Básica, focando em robótica ou na própria lógica matemática, como em [CORRÊA et al. 2015, CORDENONZI et al. 2015]. Através de projetos de ensino e da inserção de conteúdos e conceitos, é possível analisar as mudanças atitudinais dos alunos, quanto à qualidade do raciocínio e da habilidade de resolução de problemas [CORRÊA et al. 2015].

Existem também experiências sobre a Introdução ao Raciocínio Lógico por meio do ensino de Algoritmos. Em Lima e Sousa [2015] através do Programa Institucional de Bolsa de Iniciação à Docência (PIBID), os autores destacam a importância e os benefícios do desenvolvimento das habilidades em lógica e algoritmo na Educação Básica.

O presente artigo difere dos anteriores por apresentar uma experiência desenvolvida por discentes do curso de Licenciatura em Computação no Estágio Supervisionado Obrigatório I em uma escola pública de ensino fundamental que não dispunha de laboratório de informática. Além disso, os conteúdos ministrados sobre Lógica possuíam uma relação direta com a lógica de programação ao mesmo tempo que se buscou trabalhar questões da Olimpíada Brasileira de Matemática das Escolas Públicas (OBMEP), focando na lógica matemática e não apenas na resolução de questões.

\section{Materiais e Métodos}

A oficina foi realizada em uma escola pública estadual, localizada na periferia de Belém, no Estado do Pará, com o intuito de orientar os alunos do $8^{\circ}$ e $9^{\circ}$ ano do Ensino Fundamental para a Olimpíada Brasileira de Matemática das Escolas Públicas (OBMEP) no ano de 2015. Além disso, buscou-se a inserção da Computação no Ensino Básico e a familiarização com os conceitos de algoritmos e de programação mediante exemplos práticos, como atravessar a rua e trocar uma lâmpada.

O aspecto importante na elaboração do planejamento das aulas foi em relação à estrutura física da escola, que não dispunha de laboratório de informática. Todas as atividades foram desenvolvidas nas salas de aula das turmas participantes e o desafio maior para os ministrantes foi desenvolver atividades sem o uso do computador pelos alunos.

As aulas foram ministradas em duas semanas durante o mês de maio no ano de 2015, no período da tarde (mesmo turno da aula regular), antecedidas por uma semana de observação em sala de aula. Participaram da Oficina, cerca de 40 alunos, sendo 22 da turma do $8^{\circ}$ ano e 18 , do $9^{\circ}$ ano. As duas oficinas foram realizadas em 20 horas cada, totalizando 40 horas de realização de oficinas e 20 horas de observação.

O período de observação ocorreu durante as aulas das disciplinas de Matemática e Língua Portuguesa das turmas participantes das oficinas. Quanto à Matemática, constatou-se que os alunos possuíam algumas dificuldades em relação às quatro operações básicas. Já em Língua Portuguesa, apesar de terem boa leitura, apresentaram dificuldades em interpretação de texto. 
VI Congresso Brasileiro de Informática na Educação (CBIE 2017)

Anais dos Workshops do VI Congresso Brasileiro de Informática na Educação (WCBIE 2017)

A Oficina foi elaborada em quatro Unidades abrangendo os seguintes tópicos: Introdução à Lógica; Conectivos Lógicos; Operações Básicas da Matemática e Introdução ao Algoritmo de Programação. Utilizou-se diversos recursos, tais como, quadro magnético e pincel, internet e jogo on-line e impressos, projetor, cadeiras, mesas, papel, caneta, lápis, balões e palitos de fósforo.

$\mathrm{Na}$ Unidade 1, Introdução à Lógica, as atividades foram elaboradas com a utilização de palitos, dinâmicas e jogos. Primeiramente, a turma foi dividida em grupos de 5 ou 6 alunos e os desafios de lógica foram apresentados no quadro (Figura 1). As equipes receberam uma quantidade igual de palitos e o objetivo da atividade era trabalhar o raciocínio lógico de forma colaborativa.

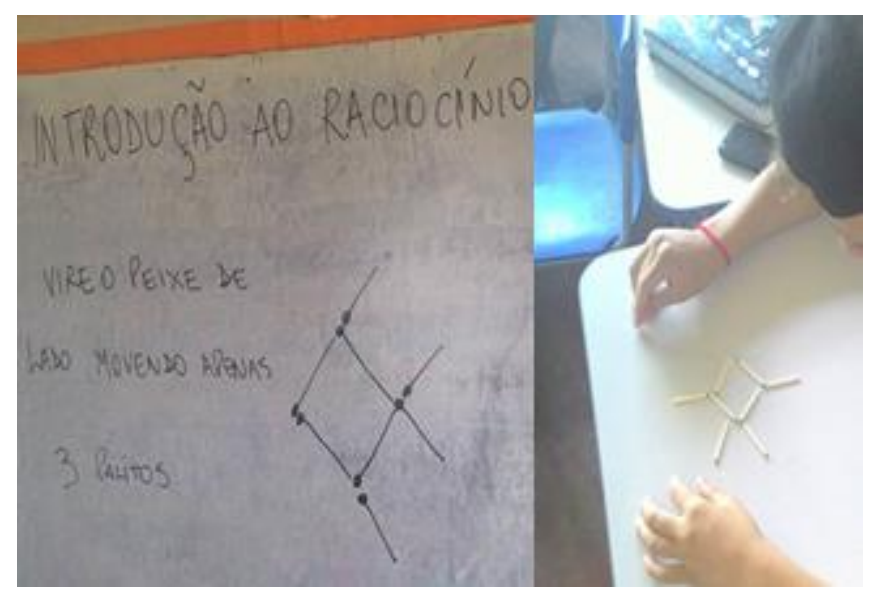

Figure 1. Exercícios de Lógica usando palitos

$\mathrm{Na}$ Unidade 2, os alunos receberam desafios individuais do Sudoku ${ }^{1}$ para trabalhar na prática os conectivos lógicos "e", "ou" e "não" e resolveram exercícios em sala, propostos em forma de desafios individuais.

Na Unidade 3, Operações Básicas da Matemática, foram utilizados o projetor e dinâmicas de interação entre os alunos. As expressões numéricas foram explanadas em sala, focando na lógica da estrutura básica e nas prioridades de resolução. Para a dinâmica, a turma organizou-se em círculo, com um ministrante de costas para a turma e dois ministrantes intermediando as atividades.

Balões com expressões numéricas escritas em papel dentro deles passavam (um em cada rodada) pelas mãos dos alunos, da direita para a esquerda. Quando o ministrante virasse de frente para a turma, o aluno que estivesse naquele momento com o balão deveria estourá-lo e resolver a expressão no quadro, com direito à ajuda dos colegas, papel e caderno para consulta (Figura 2).

\footnotetext{
1 Jogo de tabelas simples com números que devem ser organizados sem repetí-lo horizontal ou verticalmente. Disponível em: < https://rachacuca.com.br/logica/sudoku/>. Acesso em: 30 abril 2015
} 


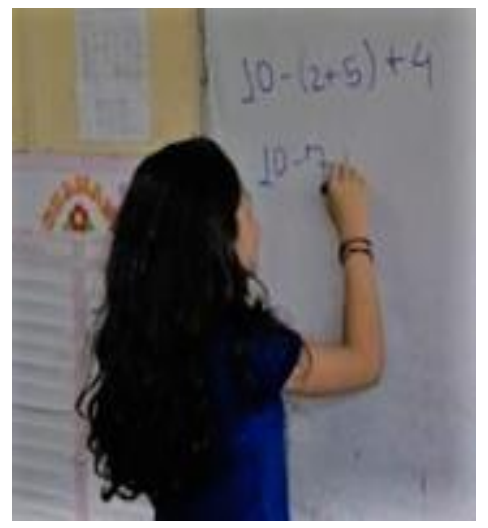

Figure 2. Aluna do 9 ํ ano resolvendo uma expressão numérica

Algumas questões da Olimpíada Brasileira de Matemática das Escolas Públicas (OBMEP) de versões anteriores foram utilizadas em sala, cujo critério de escolha das mesmas foi analisá-las logicamente (questões que pudessem ser respondidas a partir do raciocínio lógico e não apenas por fórmulas matemáticas).

$\mathrm{Na}$ Unidade 4, foi abordado o algoritmo como uma sequência finita de passos logicamente estruturados. Para fundamentar, utilizaram-se [PUGA e RISSETTI 2009] e [FORBELLONE e EBERSPÄCHER 1993], bem como o jogo "Os Missionários e os Canibais", cujo objetivo é atravessar três missionários e três canibais em um rio utilizando uma canoa que só suporta dois personagens de cada vez. Como não podem ficar mais canibais do que missionários em nenhuma das duas margens do rio, deve-se traçar o "passo a passo" para ganhar o jogo.

Os alunos escreveram a sequência de passos no caderno e utilizaram o computador e projetor para demonstrar suas respostas. A partir de atividades semelhantes, trabalhou-se a estrutura sequencial de algoritmos (linguagem Portugol) e a importância da lógica e da matemática na resolução de problemas e na Computação.

Elaborou-se um teste inicial e um teste final para as duas turmas, contendo os mesmos conteúdos e os mesmos critérios de avaliação. Também foi realizado o controle de frequência durante a oficina. Para a análise dos resultados, consideraram-se a observação das turmas, as frequências por dia de aulas, os resultados dos testes e a participação durante as oficinas.

Os testes iniciais das turmas do $8^{\circ}$ e $9^{\circ}$ ano foram formulados com três disciplinas: Língua Portuguesa, Matemática e Lógica, contendo as mesmas questões de caráter objetivo. Em Língua Portuguesa, utilizaram-se questões de semântica (interpretação de texto, sentido das palavras e expressões no contexto). Em Matemática, foram apresentadas expressões numéricas simples e jogo de sinal. Já em Lógica, trabalhou-se sequência numérica e de imagens, bem como a lógica matemática (questões da OBMEP).

\footnotetext{
${ }^{2}$ Disponível em: <http://rachacuca.com.br/jogos/missionarios-e-canibais/>. Acesso em: 30 abril 2015
} 
VI Congresso Brasileiro de Informática na Educação (CBIE 2017)

Anais dos Workshops do VI Congresso Brasileiro de Informática na Educação (WCBIE 2017)

As questões do teste inicial atenderam aos seguintes critérios: cada disciplina equivaleu a notas de 0 (zero) à 100 (cem), onde os alunos deveriam escolher qual das 5 alternativas correspondia à resposta correta. As notas dos alunos foram tabuladas e calculou-se a média de acertos por turma em cada disciplina (\%). As duas turmas realizaram o teste inicial.

Já para os testes finais, considerou-se o caráter subjetivo na elaboração das questões, com perguntas sobre a importância da lógica no dia a dia, interpretação de texto e elaboração de algoritmos sequenciais (uso da linguagem Portugol).

\section{Resultados}

Os resultados apresentados neste trabalho estão relacionados aos testes (inicial e final) realizados durante a oficina como método de avaliação (Seção 4.1), bem como a frequência e participação dos alunos durante a oficina (Seção 4.2).

\subsection{Testes: Inicial e Final}

A turma do $8^{\circ}$ ano, contemplando 16 alunos que realizaram o primeiro teste, obteve notas médias de aproximadamente 53\% em Língua Portuguesa, 63\% em Matemática e $59 \%$ em Lógica (Figura 3). A turma não realizou o teste final, devido às oficinas ocorrerem em horários vagos das turmas e haver diversas alterações quanto à disponibilidade de aulas, bem como pelo fato dos alunos iniciarem o período de avaliações escolares, seguido do período de férias.

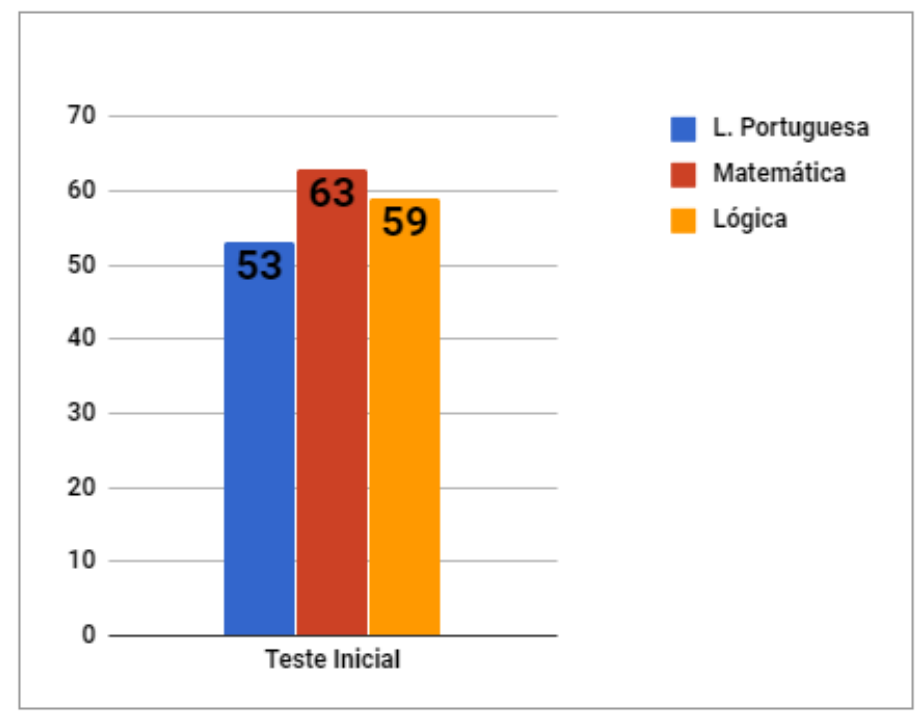

Figure 3. Notas do Teste Inicial (\%) - Turma do 8 Ano

Na turma do $9^{\circ}$ ano, 17 alunos realizaram o teste inicial, obtendo notas médias de aproximadamente $60 \%$ em Língua Portuguesa, 65\% em Matemática e $65 \%$ em Lógica. Durante a oficina dessa turma, não houve tantas alterações de horários de aulas 
VI Congresso Brasileiro de Informática na Educação (CBIE 2017)

Anais dos Workshops do VI Congresso Brasileiro de Informática na Educação (WCBIE 2017)

quanto às da turma do $8^{\circ}$ ano, realizando-se assim, o teste final e coletando-se os resultados.

Considerando o mesmo critério de notas dos testes iniciais (nota máxima igual a $100)$, os alunos obtiveram no teste final nota média de aproximadamente $66 \% \mathrm{em}$ Língua Portuguesa; 33\% em Matemática e 49\% em Lógica (Figura 4). Ao contrário do teste inicial, as questões dos testes finais foram formuladas de forma subjetiva, abordando o conceito e a importância da lógica no dia a dia, tabela dos conectivos lógicos, interpretação de texto e elaboração do algoritmo em sequência de passos.

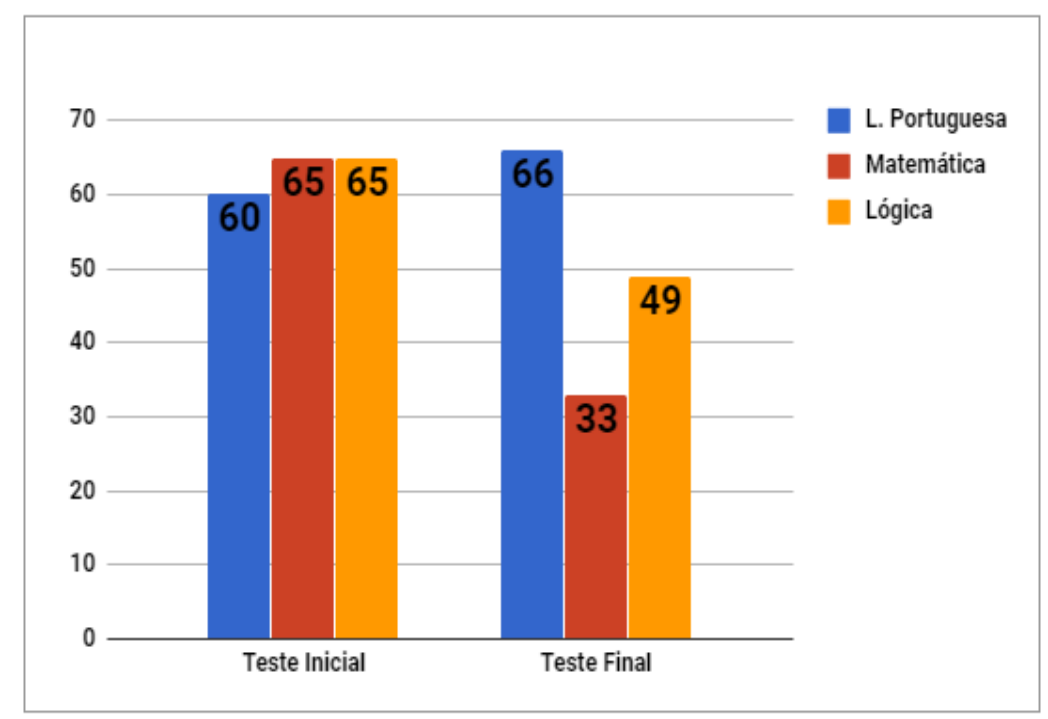

Figure 4. Notas do Teste Inicial e Final (\%) - Turma do 9 Ano

A diferença entre nota inicial e final de parte dos alunos do $9^{\circ}$ ano deve-se ao tipo de questões elaboradas, onde os testes iniciais foram compostos apenas de questões objetivas e os testes finais possuíam questões subjetivas. Apesar da queda da nota média de alguns alunos, notou-se que a prática do raciocínio lógico obteve uma mudança positiva, bem como a habilidade de resolução de problemas.

A partir dos resultados dos testes inicial e final da turma do $9^{\circ}$ ano, pode-se notar que houve aumento da nota em Língua Portuguesa, onde os alunos formularam a interpretação de texto, definiram lógica e sua importância e conceituaram algoritmo de programação. Quanto às notas de Matemática e Lógica, no decorrer da oficina percebeuse que parte dos alunos não havia de fato conseguido responder algumas das questões do teste inicial, escolhendo assim uma das alternativas e coincidentemente, acertando algumas questões de forma aleatória, um dos motivos pelos quais optou-se por realizar testes finais com questões subjetivas.

A turma do $8^{\circ}$ ano, apesar de não ter realizado o teste final, demonstrou-se bastante participativa durante as atividades, com melhora significativa na escrita, na formulação de respostas às questões subjetivas e na interpretação de textos. Obteve, assim como a turma do $9^{\circ}$ ano, uma mudança positiva em resolução de expressões numéricas e desafios de lógica, bem como no modo de ver a Computação e o raciocínio 
VI Congresso Brasileiro de Informática na Educação (CBIE 2017)

Anais dos Workshops do VI Congresso Brasileiro de Informática na Educação (WCBIE 2017)

lógico no dia a dia, reconhecendo a importância de estudar lógica nas escolas e de utilizar o pensamento computacional em situações diversas.

As duas turmas realizaram a Olimpíada Brasileira de Matemática (OBMEP), porém a escola não disponibilizou oficialmente os resultados. Os alunos das duas turmas relataram que obtiveram maior facilidade em resolver algumas questões que envolveram a lógica matemática e que as oficinas realizadas na escola obtiveram bons resultados para suas vidas.

\subsection{Frequência}

A frequência é um fator importante para verificar a participação e motivação dos alunos no decorrer da oficina, pode-se observar no gráfico (Figura 5) nas duas turmas a boa frequência dos alunos, destacaram-se por apresentarem média percentual acima de $80 \%$. Acredita-se que esta média possa estar relacionada ao desenvolvimento das aulas dinâmicas.

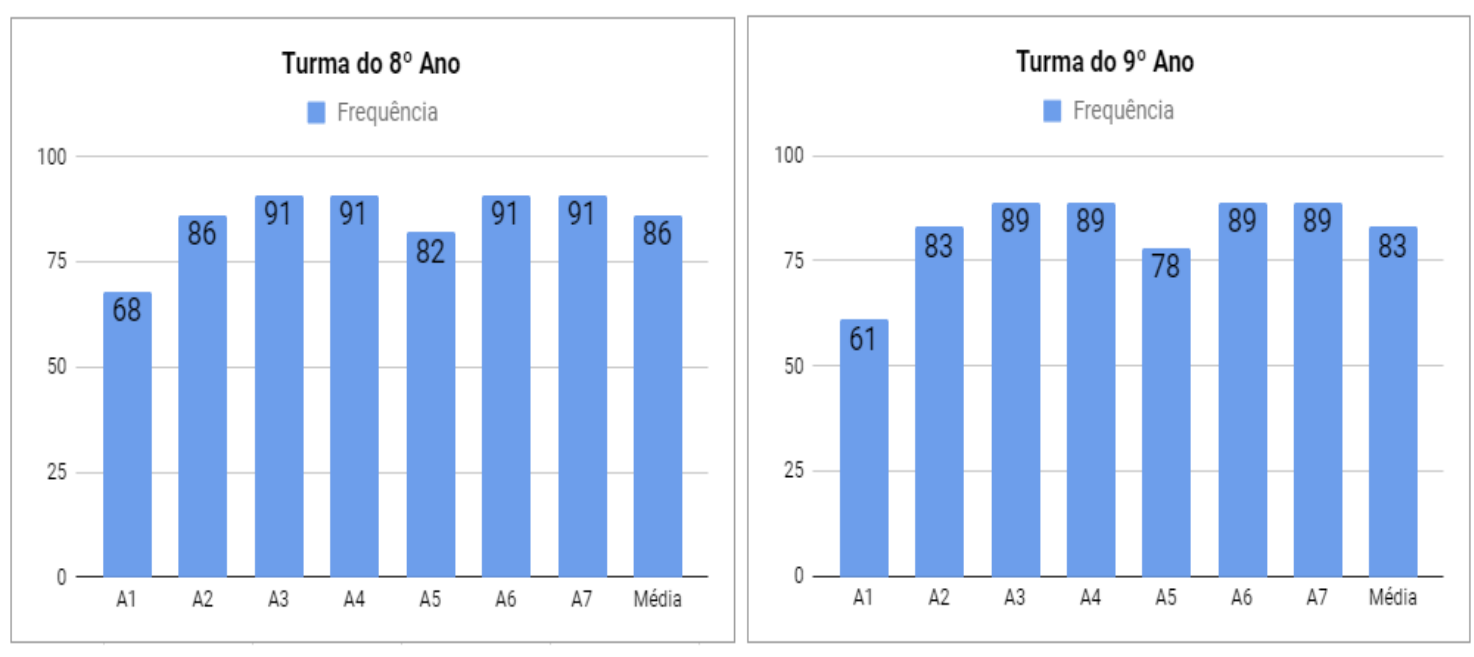

Figure 5. Frequência das Turmas (\%)

Quanto às menores médias, em apenas duas aulas ocorreu maior retenção de alunos (Aulas 1 e 5). Durante a Aula 1 obteve-se aproximadamente 68\% do total de alunos do $8^{\circ}$ ano e aproximadamente $61 \%$ de alunos do $9^{\circ}$ ano; já na Aula 5, obteve-se aproximadamente $82 \%$ dos alunos do $8^{\circ}$ ano e aproximadamente $78 \%$ dos alunos do $9^{\circ}$ ano. A retenção justifica-se pelo período de aulas regulares em que o aluno estavam, que acabou coincidindo com o das atividades da oficina.

Quanto à participação nas atividades, as duas turmas apresentaram bom relacionamento durante as dinâmicas em grupo, auxiliando os colegas que apresentavam alguma dificuldade e boa competitividade em relação aos desafios propostos. 
VI Congresso Brasileiro de Informática na Educação (CBIE 2017)

Anais dos Workshops do VI Congresso Brasileiro de Informática na Educação (WCBIE 2017)

\section{Considerações Finais}

O artigo apresentou a experiência realizada no Estágio Supervisionado Obrigatório do Curso de Licenciatura em Computação, através do pensamento computacional para auxiliar os alunos da Educação Básica na OBMEP. Após a olimpíada, não foi possível obter as notas para verificar se houve bom rendimento por meio das intervenções e comparar com as edições anteriores.

Percebemos que através de dinâmicas e do conceito de lógica é possível contextualizar sobre diversos aspectos do cotidiano, como português, matemática, ética na escola (respeito a regras e aos colegas, informações coletadas pelas redes sociais e aplicativos, entre outros) e trabalhar a interdisciplinaridade.

Apresentar aos alunos a Computação de forma lúdica é importante até para a compreensão sobre como utilizar as tecnologias de maneira consciente e estimular a descoberta e o interesse pela área. Também proporciona a desmitificação e aproximação da Computação à realidade dos alunos.

O ensino da Computação tem por objetivo transformar a Educação. A proposta do ensino de Computação vai além do domínio do aluno à máquina, abrange a utilização desta ferramenta para pensar, (re)descobrir a realidade e construir conhecimento, ampliando sua visão de mundo e, assim talvez, criando uma visão mais crítica e transformadora.

Neste cenário de transformação é que o Licenciado em Computação tem um papel crucial, pois ele estará inserido neste ambiente escolar a fim de permitir que os alunos tenham acesso a estes conhecimentos. Cabe a ele auxiliar no processo de ressignificação dos códigos, linguagens e tecnologias. O cenário em que está incluído o Licenciado em Computação demonstra de forma clara que ele já não é mais o detentor do conhecimento, mas aquele que tem o domínio das ferramentas que levarão ao conhecimento.

Como Licenciandos em Computação consideramos que a detenção dos conhecimentos que envolvem a Computação, como lógica e princípios básicos de programação são capazes de transformar o aluno em um cidadão mais crítico e com uma visão de mundo mais ampla. Como a escola é um ambiente que favorece a transformação social, logo, acreditamos que o ensino da Computação possa gerar uma transformação social.

Como trabalhos futuros, pretendemos aplicar a Oficina em turmas de séries iniciais do Ensino Fundamental em escolas públicas e privadas, com o intuito de analisar os diferentes ambientes escolares e quais os impactos causados dentro ou fora das escolas. Também pretendemos realizar uma análise mais profunda de como o ensino de Computação e de raciocínio lógico pode influenciar no desempenho dos alunos em disciplinas como a Matemática e a Língua Portuguesa.

\section{Referências}

BARCELOS, Thiago Schumacher; SILVEIRA, Ismar Frango. Pensamento computacional e educação matemática: Relações para o ensino de computação na 
VI Congresso Brasileiro de Informática na Educação (CBIE 2017)

Anais dos Workshops do VI Congresso Brasileiro de Informática na Educação (WCBIE 2017)

educação básica. In: XX Workshop sobre Educação em Computação, Curitiba. Anais do XXXII CSBC. 2012. p. 23.

BELl, Tim; WITTEN, Ian H.; FELlOWS, Mike. Computer Science Unplugged. Ensinando Ciência da Computação sem o uso do computador. Tradução coordenada por Luciano Porto Barreto, 2011.

BEZERRA, Fábio. Bem mais que os bits da computação desplugada. In: Anais do Workshop de Informática na Escola, Dourados, MS. 2014. p. 116.

CHAVES, Eduardo Oscar et al. Projeto Educom: Proposta Original. Memos do NIED, v. 1, n. 1, 1983.

CORDENONZI, Walkiria et al. Uma Experiência Interdisciplinar no Ensino de Algoritmos e Matemática em um Contexto Binacional. In: Anais dos Workshops do Congresso Brasileiro de Informática na Educação. 2015. p. 1408.

CORRÊA, Renata et al. Desenvolvimento de Projetos em Robótica Educacional a inserção da Expressão Gráfica no ensino. Anais temporários do LACLO 2015, v. 10, n. 1, p. 257, 2015.

FORBELlONE, André Luiz Villar; EBERSPÄCHER, Henri Frederico. Lógica de programação: a construção de algoritmos e estruturas de dados. Makron Books, 1993.

FRANÇA, RS de; SILVA, WC da; AMARAL, HJC do. Ensino de ciência da computaçao na educaçao básica: Experiências, desafios e possibilidades. In: XX Workshop sobre Educação em Computação. 2012.

LIMA, Árllon Chaves; DE SOUSA, Decíola Fernandes. Experiência no programa institucional de bolsas de iniciação à docência (pibid): Desenvolvimento do raciocínio lógico e algoritmo na educação básica. In: Anais dos Workshops do Congresso Brasileiro de Informática na Educação. 2015. p. 1290.

MANSO, António; OLIVEIRA, Luís; MARQUES, C. Portugol IDE-Uma ferramenta para o ensino de programação. In: PAEE'2009-Project Approaches in Engineering Education-Guimaraes. 2009.

PAULA, LQ de; PIVA JR, Dilermando; FREITAS, Ricardo L. A Importância da Leitura e da Abstração do Problema no processo de formação do raciocínio lógico-abstrato em alunos de Computação. In: XVII Workshop sobre Educação em ComputaçãoWEI. 2009.

PUGA, Sandra; RISSETTI, Gerson. Lógica de programação e estruturas de dados com aplicações em Java. Pearson Prentice Hall, 2009.

RAIOL, Alberto Alan et al. Experiências de Ensino da Computação Desplugada em Diferentes Séries da Educação Fundamental Maior. In: XVII Workshop sobre Educação em Computação-WEI. 2016. 